\title{
Reading Strategies, Reading Comprehension, and Translation
}

\author{
Gabriella KOVÁCS \\ Sapientia Hungarian University of Transylvania (Cluj-Napoca, Romania) \\ Department of Applied Linguistics \\ kovagabi@yahoo.com
}

\begin{abstract}
Translators and language teachers are cultural and intercultural mediators, facilitators of intercultural transfers and border crossings between cultures. The abilities to understand, interpret, and produce written texts appropriately play an essential role in these professions. In the process of translation, source-language texts have to be understood and translated using the most appropriate target-language equivalents. Reading skills and awareness of reading strategies are equally essential for language teachers, who are expected to guide language learners in developing these skills. In this study, we intend to examine the reading habits and reading strategies used by a group of Hungarian translator and teacher trainees when dealing with texts written in English. Their reading comprehension performance will be assessed with a test and compared with their ability to translate English texts into Hungarian. Based on the literature and our personal experience in language teaching, teacher training, and translator training, we assume that students preparing for the above mentioned professions have a well-developed reading strategy awareness and that their reading comprehension skills in English strongly influence the ability to translate texts into their native language.
\end{abstract}

Keywords: reading comprehension skills, reading strategies, translation, translator training, teacher training.

\section{Introduction}

Language teacher and translator trainees study to equip themselves with the skills, strategies, and experience necessary for their future profession. Ideally, they choose this domain because they are interested in and open to other cultures and languages, and they plan to help others in crossing the borders between cultures.

The subjects of this study are translation and interpretation students at Sapientia Hungarian University of Transylvania, Faculty of Technical and Human Sciences, and most of them take part in a teacher training programme as well. One of the 
entrance exam criteria is that their level of English should be B2 or above, but in our experience not all of them meet this requirement. Nevertheless, they are accepted if there are available places. Therefore, in the training process, we have to take into consideration the fact that some of them may face difficulties resulting from their inadequate language skills, including reading comprehension.

Reading is one of the important skills that teacher and translator trainees will need in their future profession. If they become translators, they will have to comprehend the source-language texts well enough to be able to translate them using the most appropriate target-language equivalents. If they become teachers, reading skills and awareness of reading strategies are equally essential because they will be expected to guide language learners in developing these skills and strategies.

In this study, we present a survey of the reading habits of our target group and their reading strategy awareness when reading academic materials or textbooks written in English. Their reading strategies were assessed with an instrument developed by Mokhtari and Sheorey (2002). We also measured their reading comprehension level and translation skills with a test. Correlation was measured between their reading comprehension level and their ability to translate English texts into Hungarian. According to Pham (2017), the relations between reading comprehension and translation were examined in other studies as well, and in most cases a significant correlation was found between them. The purpose of this study is to assess and examine our students' possible needs and weaknesses and to take in consideration any such factors in future curriculum design.

\section{Reading comprehension, reading strategies, and translation}

Reading comprehension is one of the essential skills that language learners have to develop. In the history of language teaching, there have been several attempts to categorize and describe the language skills necessary for communication. Bárdos (2005), for example, proposed a model which includes six skills divided into three levels, where each level includes the previous ones: the level of understanding (listening and reading comprehension), the level of conveying a message or communicating (writing and speaking), and the level of mediation (translation and interpretation). As this model suggests, reading is an essential skill, necessary for the development and practice of the other skills. However, as Hinkel pinpoints it, today, when the dominant idea is integrated language teaching based on communication-oriented principles, "after decades of research in language teaching and learning, it seems clear that, in many cases and for many purposes, the separation of the four macro skills is likely to be less effective than integrated instruction simply because, in reality, communication does not 
take place in terms of discrete linguistic skills" (2010: n. p.). Therefore, ideally, reading is developed together with the other skills, but reading skills and strategy awareness may be more important for students such as translators, whose future profession will consist mainly of working with written texts.

Reading comprehension is a complex process and may be influenced by several factors. According to Bárdos (2000), reading cannot be regarded simply as a mechanical, automated process of recognizing certain signs and the meaning of the different words. It is a more complex endeavour, involving interpretation, the attempt to reveal the communicative function of the text, namely the intention of the writer. He believes that we may consider four levels regarding reading in a foreign language: the level of physically recognizing the letters; recognizing, decoding the meaning of the word; the level of understanding the meaning of the word, considering the grammatical aspects as well; the level of text interpretation, including reaction. However, the understanding of a text may also depend on the reader's language proficiency, cultural competence, background knowledge, and area of interest.

Grabe (2014) proposes a set of principles and several instructional approaches that may be useful in developing second-language reading skills. Among other principles, he suggests that the curriculum should be based on the needs of the students and the objectives of the teaching process, using plentiful, effective, varied, and interesting reading resources and teaching materials. He proposes the following developmental goals: promoting word recognition skills, building an abundant recognition vocabulary, practising comprehension skills, building awareness of discourse structure, promoting strategic reading, practising reading fluency, developing extensive reading, developing motivation, and combining language learning with content learning.

In the process of translation, when a message has to be conveyed from the source language into the target language, advanced reading skills are essential. As Newmark recommends, the work of translating a text starts with its analysis, first of all, with a careful reading. "You begin the job by reading the original for two purposes: first, to understand what it is about; second, to analyse it from a translator's point of view, which is not the same as a linguist's or a literary critic's. You have to determine its intention and the way it is written for the purpose of selecting a suitable translation method and identifying particular and recurrent problems" (1988: 11). He states that both general reading and close reading are necessary in order to understand a text appropriately. The general approach helps the reader to discover the main concepts, the essential ideas of the text, and for this it may be necessary to find and consult other sources of information as well. Close reading means that any challenging words, terms, or expressions have to be looked up and their meaning must be clarified. Therefore, reading a text with the purpose of translating is not an easy task. "You can compare the translating 
activity to an iceberg: the tip is the translation - what is visible, what is written on the page - the iceberg, the activity, is all the work you do, often ten times as much again, much of which you do not even use” (Newmark 1988: 12).

Rainer Schulte, a professor of translation studies who has made a significant contribution to the art of translation, writes in an essay about translation and reading that translators develop...

reading techniques that are distinctly different from those of a critic and scholar. First of all, we are dealing with a level of intensity. Translators look at each word through the lens of a magnifying glass. [...] Reading is a continuous process of translation, and the way the translator looks at every word and investigates its rhythmic power and its semantic possibilities reaffirms that the act of reading, seen through the translator's eyes, is dynamic and not static. The writer creates the text and the reader as translator is involved in a constant process of re-creating the text. ${ }^{1}$

Reading habits, language proficiency, reading skills, and awareness of strategies may all be developed and further shaped in the process of translator and teacher training, but for this it is necessary to examine the needs and the level of the target group.

\section{The instruments of the survey}

The first part of the survey consisted of a questionnaire in which we requested general information about the students' age, gender, year of study, their self-rated level of English, whether they studied other foreign languages, how and where they had learned English (school, private language school, by themselves, with a private tutor), whether living in a bilingual region (Hungarian-Romanian) had helped them in learning a third language (English), which task would be the most difficult for them at an English language examination (reading comprehension, writing, use of English, listening comprehension, or speaking), and, given that they still had to improve their English, which language learning activity they considered the most useful in preparing them for their future career (grammar, vocabulary, reading, listening, speaking, writing, or translation activities). Related to reading, we asked the following: how difficult it is for them to comprehend texts written in English compared to texts written in their native language, Hungarian, how frequently they use libraries, and what types of texts they usually read in English.

The second part of the questionnaire consisted of the Survey of Reading Strategies (SORS), an instrument designed by Mokhtari and Sheorey (2002),

1 http://translation.utdallas.edu/essays/reading_essay1.html 
intended to survey students' perceived use and awareness of reading strategies mainly when reading textbooks or academic texts related to their studies. The reliability and validity of this instrument was tested and demonstrated by its authors. An advantage of SORS is that it may also help students develop a better awareness of their reading strategies and realize if there are any strategies which they have not used before but could be helpful in improving their reading efficiency. SORS consists of thirty questions, which can be answered by using a five-point scale ranging from "I never do this" to "I always do this". The frequency of the use of a certain strategy is shown by the chosen number - the higher it is, the more frequently the respective strategy is used by the student. The instrument measures three different categories. Global Reading Strategies (GLOB) are planned, intentional techniques, measured with thirteen items. Problem-Solving Strategies (PROB) refer to procedures and actions used by readers while working with a text, measured with eight items. Support Strategies (SUP) are actions which may help the reader in comprehending the text, measured with nine items.

Reading comprehension was measured with the help of two tasks taken from a B2-level ECL sample test. ${ }^{2}$ At this level, candidates are expected to demonstrate their ability to understand specific information and to recognize the purpose and tone of texts taken from different sources such as newspapers, magazines, reports, regulations, or formal letters. ${ }^{3}$ In the first task, students had to read a gapped text and find the right part to each blank space from a given list, where more possible parts were given than they needed. In the second task, they had to read a text and answer ten questions using maximum seven words in each answer. The maximum score for the test was 25 points. In ECL exams, each skill (reading, writing, listening, and speaking) is allocated 25 points; hence, the total score achievable is 100 . The exam is considered successful if candidates reach a minimum of $60 \%$ overall in the four skills. ${ }^{4}$ Our purpose with this task was to measure whether our students' reading skills correspond to the expected B2 level and to examine whether their performance in these tasks correlate with their performance in translation.

In order to assess our students' translation skills, they were asked to translate three paragraphs (consisting of approximately 200 words) from the second text of the reading comprehension text. Their performance was scored using a 1-to10 scale.

2 http://eclexam.eu/files/ReadingB2.pdf

3 http://eclexam.eu/parts-of-the-exam/

4 http://eclexam.eu/exam-assessment/ 


\section{Results}

The questionnaire and test were completed by 57 translation and interpretation students at Sapientia Hungarian University of Transylvania, Faculty of Technical and Human Sciences, most of whom take part in a teacher training programme as well (20 first-year students, 22 second-year students, and 15 third-year students).

$40 \%$ of the students study not only English but other foreign languages as well (German or Danish), and they have all studied Romanian, the official language of the country. When they graduated from high school, they all had to take an examination in Romanian and another foreign language they had studied, in our target group's case, mainly English. Therefore, they may be considered experienced language learners, aware of their language proficiency and of their strengths and weaknesses. They have studied these languages mainly at school or at university, but the majority also mentions other ways such as with the help of a private tutor, individual studies, or with the help of television, the Internet, and videogames. Regarding their self-rated level of English, 31.5\% of the respondents master the language on advanced (C1) level, $31.5 \%$ on upper-intermediate (B2) level, $33.5 \%$ on intermediate (B1) level, and $3.5 \%$ on pre-intermediate (A2) level. According to the answers, $36 \%$ are not at the ideal level for their studies.

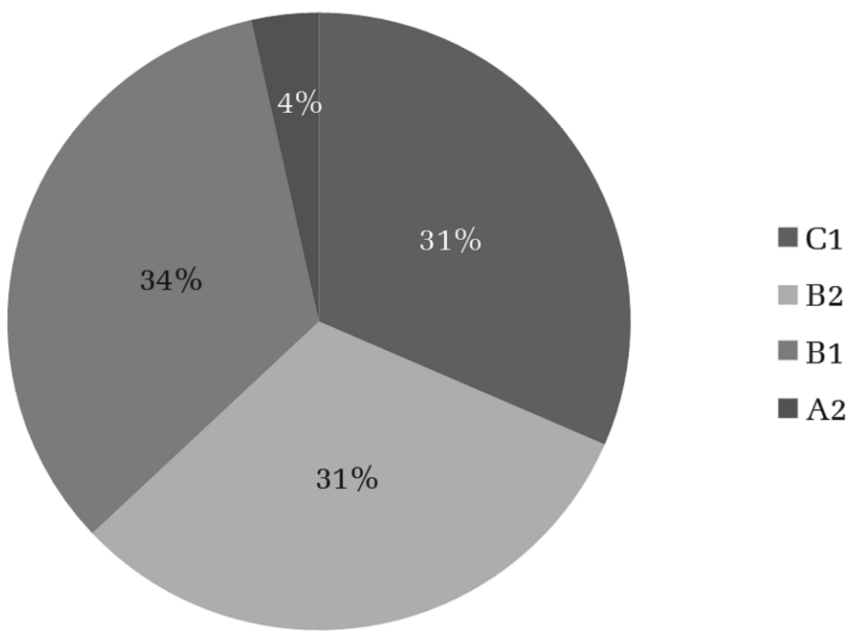

Figure 1. Respondents' self-rated level of English

To the question "Which task do you find the most difficult in a language exam?", $38.5 \%$ of the respondents chose listening comprehension, $35 \%$ writing, $17.5 \%$ speaking, and only $9 \%$ chose reading comprehension. 




Figure 2. The most difficult task in a language exam

This confirms our experience that reading activities are fairly popular among students, and when their language skills are assessed the majority of the students achieve higher scores in reading comprehension and speaking than in listening comprehension and writing. However, the majority (83\%) of the students declared that they found it more difficult to understand texts written in English than in Hungarian, 5\% stated that they found it significantly more difficult, and only $12 \%$ claimed that they understood texts written in English almost as easily as in their native language, which would be the ideal and expected performance in the case of a teacher or translator.

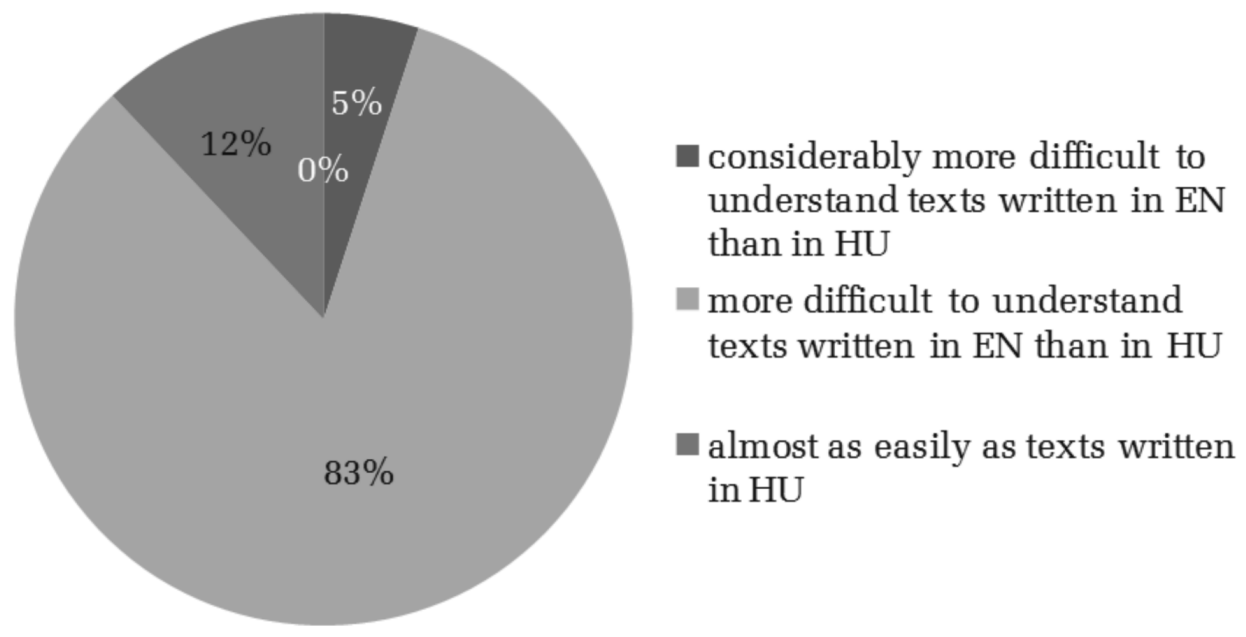

Figure 3. Understanding EN vs HU texts 
To the question "How often do you use the library?", 40.5\% answered "never", $54.5 \%$ "occasionally", and only $5 \%$ answered "regularly", which may raise further questions about the quality of library services regarding the availability of the necessary materials our students need for their studies but also about students' preference for online sources. Their limited interest and motivation in consulting a wider recommended literature regarding a certain subject besides the course materials received from their teachers may be another problem.

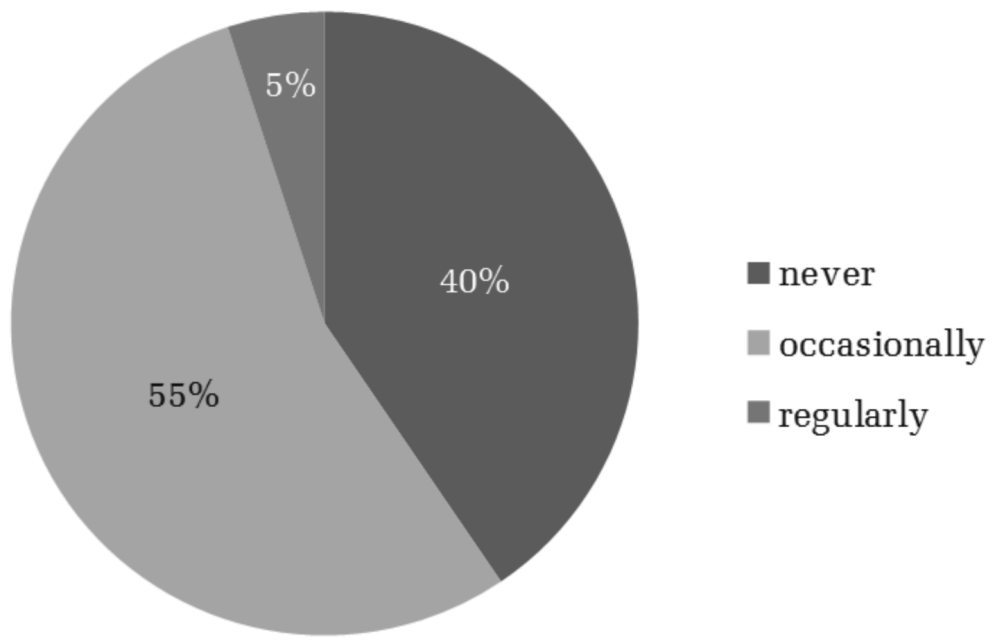

Figure 4. Frequency of visits to the library

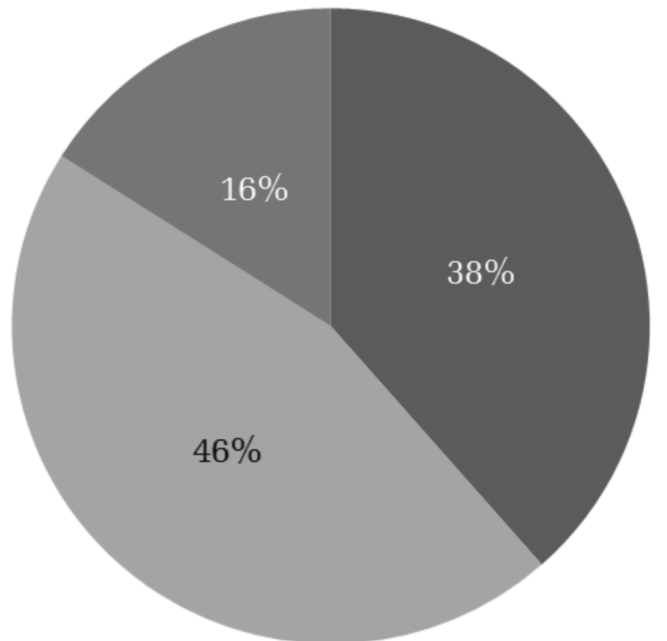

novels, short stories

online and print media products

academic texts

Figure 5. What do they read in English? 
The answers to the next question related to the type of texts they read in English may also explain why they do not use the library regularly. $84 \%$ of the respondents read for entertainment (38.5\% prefer literature, mainly novels and short stories, and $45.5 \%$ read online and print media), while only $16 \%$ of them read academic texts written in English (articles, essays, textbooks, monographs).

The students had to choose two language learning activities from a list of seven (grammar, vocabulary, reading comprehension, listening comprehension, speaking, writing, translation), which they found most useful in preparing for their future career.

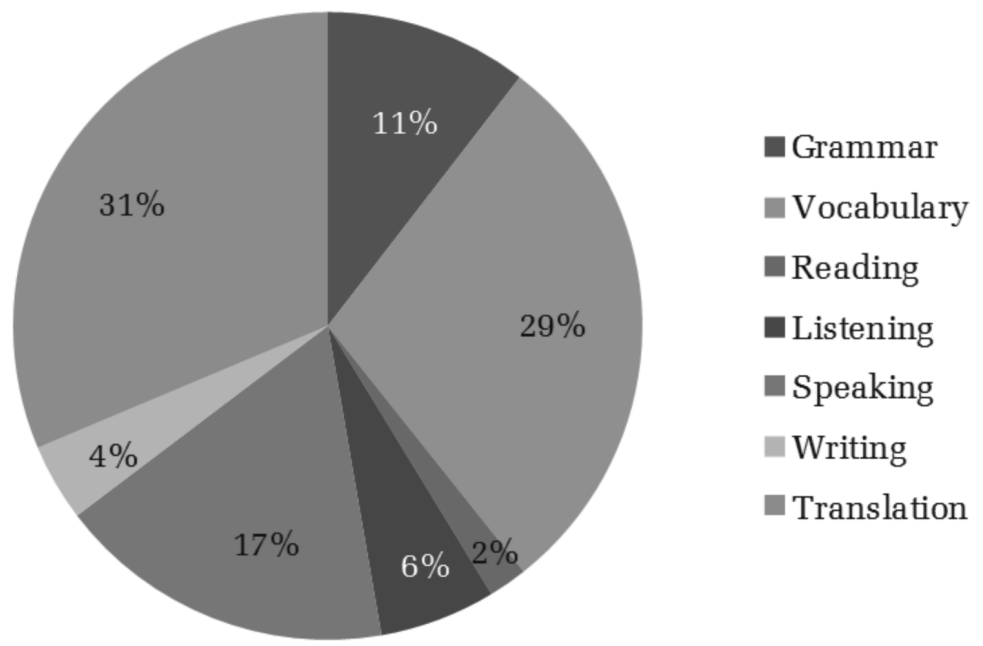

Figure 6. Useful activities for future career

These choices may be influenced by the activities they are most frequently required to do in their training process, namely translation exercises and glossarybuilding activities. The most rarely chosen activity was reading, which may result from the fact that they feel confident in comprehending written texts. This would confirm their answers to a previous question, where only a few students labelled reading comprehension as the most difficult task in a language examination.

The next set of 30 questions measured students' perceived use and awareness of reading strategies when reading textbooks or academic texts related to their studies. The score averages were interpreted for each category separately and for the whole instrument according to the levels suggested by the authors (Mokhtari and Sheorey 2002) who developed the instrument: High = mean of 3.5 or higher, Moderate $=$ mean of 2.5 to 3.4, and Low $=$ mean of 2.5 or lower.

The thirteen items measuring Global Reading Strategies (GLOB) are the following: I have a purpose in mind when I read; I think about what I know to help me understand what I read; I take an overall view of the text to see what 
it is about before I read it; I think about whether the content of the text fits my reading purpose; I review the text first by noting its characteristics like length and organisation; when reading, I decide what to read closely and what to ignore; I use tables, figures, and pictures in text to increase my understanding; I use context clues to help me better understand what I am reading; I use typographical features like bold face and italics to identify key information; I critically analyse and evaluate the information presented in the text; I check my understanding when I come across new information; I try to guess what the content of the text is about when I read; I check to see if my guesses about the text are right or wrong. The results show that all students are aware of the usefulness and importance of these strategies, and they use most of them as often as necessary in order to comprehend academic texts and school materials more efficiently. None of them showed a lack of awareness of these techniques.

Table 1. Global Reading Strategies

\begin{tabular}{ccc}
\hline Mean & Number of students & $\%$ \\
\hline High & 23 & $40.35 \%$ \\
\hline Medium & 34 & $59.65 \%$ \\
\hline Low & 0 & $0 \%$ \\
\hline
\end{tabular}

The eight items measuring Problem-Solving Strategies (PROB) are the following: I read slowly and carefully to make sure I understand what I am reading; I try to get back on track when I lose concentration; I adjust my reading speed according to what I am reading; when text becomes difficult, I pay close attention to what I am reading; I stop from time to time and think about what I am reading; I try to picture or visualize information to help remember what I read; when text becomes difficult, I reread it to increase my understanding; when I read, I guess the meaning of unknown words or phrases. According to the answers given, 80\% of the respondents are aware of using these techniques while reading academic texts or school materials, and they use them frequently.

Table 2. Problem-Solving Strategies

\begin{tabular}{ccc}
\hline Mean & Number of students & $\%$ \\
\hline High & 46 & $80.70 \%$ \\
\hline Medium & 10 & $17.54 \%$ \\
\hline Low & 1 & $1.75 \%$ \\
\hline
\end{tabular}

The nine items measuring Support Strategies (SUP) are the following: I take notes while reading to help me understand what I read; when text becomes difficult, I read aloud to help me understand what I read; I underline or circle information in the text to help me remember it; I use reference materials (e.g. a dictionary) to help 
me understand when I read; I paraphrase (restate ideas in my own words) to better understand what I read; I go back and forth in the text to find relationships among ideas in it; I ask myself questions I like to have answered in the text; when reading I translate from English into my native language; when reading I think about information in both English and my mother tongue. Based on the answers, students seem to find Support Strategies less important than the other two categories. The reason for this may be that they are experienced readers, and therefore they do not need to use these strategies as frequently as the ones from the previous categories.

Table 3. Support Strategies

\begin{tabular}{ccc}
\hline Mean & Number of students & $\%$ \\
\hline High & 22 & $38.60 \%$ \\
\hline Medium & 27 & $47.37 \%$ \\
\hline Low & 8 & $14.04 \%$ \\
\hline
\end{tabular}

The score averages for the whole instrument and group means for the three strategies show that our students possess the necessary reading strategies for efficient comprehension of textbooks or academic texts related to their studies.

Table 4. The score averages for the whole instrument

\begin{tabular}{ccc}
\hline Mean & Number of students & $\%$ \\
\hline High & 29 & $50.88 \%$ \\
\hline Medium & 28 & $49.12 \%$ \\
\hline Low & 0 & $0.00 \%$ \\
\hline
\end{tabular}

Table 5. The group's means for the three strategies and the overall mean

\begin{tabular}{cccc}
\hline GLOB & PROB & SUP & Overall \\
\hline 3.39 & 3.94 & 3.21 & 3.49 \\
\hline
\end{tabular}

After the questionnaire was completed, the questions from the Survey of Reading Strategies (SORS) were discussed with the students in order to increase their awareness of reading strategies and their understanding of the reading process. They were encouraged to use any of the techniques which they had not used before and would consider useful in order to comprehend texts more efficiently.

In the reading comprehension test, only 8 students (4.5\%) did not reach the minimum of $60 \%$, which means that the scores of the majority correspond to the required B2 level. However, for most students, the first task, where they had to read a gapped text and find the right part to each blank space from a given list, proved less difficult than the second one, where they had to read a text and answer ten questions using maximum seven words in each answer. While 23 students managed to answer all the questions correctly in the first task, only 8 were awarded 
a maximum score for the second task. Most of the unacceptable answers indicate that students failed to understand and interpret correctly certain parts of the text.

The translation task was rated on a 1-to-10 scale. 8 students received 10 points, but translations awarded with 8 or 9 points were also acceptable, without considerable misinterpretations of the source text. Therefore, it can be said that a total of 32 students $(56.2 \%)$ produced acceptable translations. Translations awarded only with 6 or 7 points (19 students, 33.3\%) contained misinterpretations of certain phrases or sentences, which slightly affected the overall meaning of the passage. The 6 students $(10.5 \%)$ who received less than 6 points produced unacceptable translations containing several misinterpreted phrases and sentences, which significantly altered the overall message and meaning of the target text.

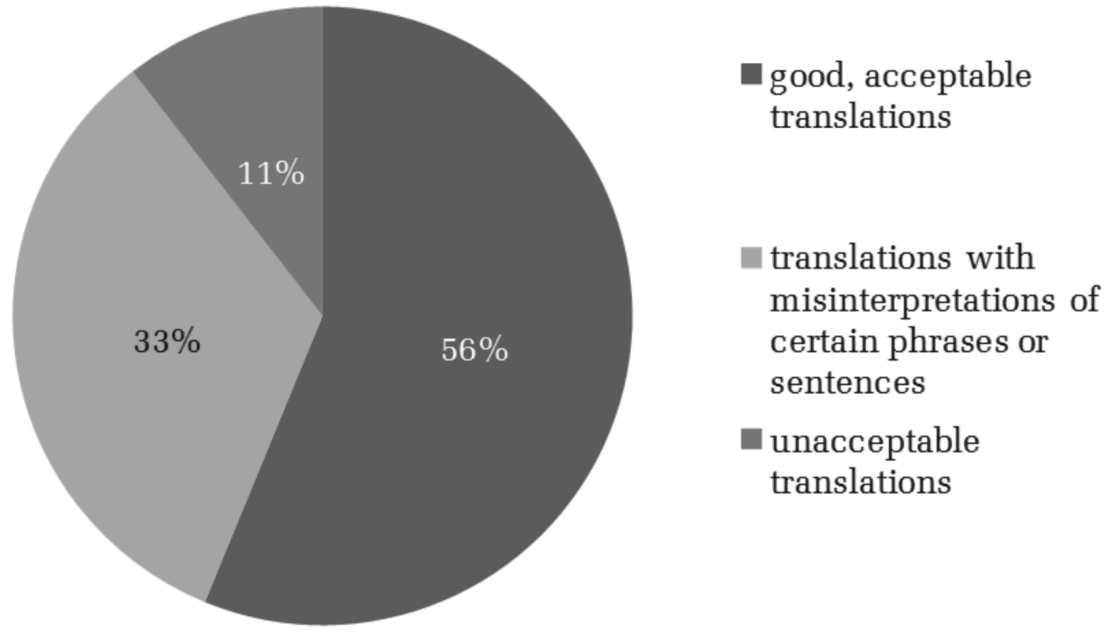

Figure 7. Translations

The unacceptable translations and misinterpretations were often the result of the lack of comprehension of the source language text.

A moderate correlation $(\mathrm{r}=0.626)$ was found between students' scores achieved in the reading comprehension task and the translation task. This confirms our assumption based on experience that students' reading comprehension skills in English influence the ability to translate texts into Hungarian, and it confirms that reading comprehension influences translation performance.

\section{Conclusions}

In conclusion, we can say that the analysis revealed or confirmed some potential problems which should be addressed in the curricular or extracurricular teaching- 
learning process and curriculum development. These are the following: some of the students must be helped and encouraged to improve their language skills and reach a performance level which is adequate for a translator or language teacher; students should be encouraged to use the library more often and read more academic texts related to their studies (such as articles, essays, textbooks, monographs), which may help them in preparing for their future career; students must be aware of the importance of reading comprehension skills and strategies in translation and language teaching, and these skills must be further developed if necessary; the set of questions from the Survey of Reading Strategies (SORS) can be used to increase students' awareness of reading strategies and their understanding of the reading process.

\section{References}

Bárdos, Jenő. 2000. Az idegen nyelvek tanításának elméleti alapjai és gyakorlata [The Theory and Practice of Foreign Language Teaching]. Budapest: Nemzeti Tankönyvkiadó.

2005. Élố nyelvtanítás-történet [A History of Language Teaching]. Budapest: Nemzeti Tankönyvkiadó.

Grabe, William. 2014. Key issues in L2 reading development. In Xudong Deng, Richard Seow (eds), $4^{\text {th }}$ CELC Symposium Proceedings, 8-18.

http://www.nus.edu.sg/celc/research/books/4th\% 20 Symposium $\% 20$ proceedings/2).\%20William\%20Grabe.pdf. (Last accessed: 5 May 2018).

Hinkel, Eli. 2010. Integrating the four skills: Current and historical perspectives. In R. B. Kaplan (ed.), Oxford Handbook in Applied Linguistics, 110-126. $2^{\text {nd }}$ ed. Oxford University Press. http://www.elihinkel.org/downloads.htm. (Last accessed: 2 May 2018).

Mokhtari, Kouider-Sheorey, Ravi. 2002. Measuring ESL students' awareness of reading strategies. Journal of Developmental Education 25(3): 1-10.

https://www.researchgate.net/publication/285641803_Measuring_ESL_ students\%27_awareness_of_reading_strategies. (Last accessed: 6 May 2018).

Newmark, Peter. 1988. A Textbook of Translation. New York, London, Toronto, Sydney, Tokyo: Prentice Hall.

Pham, Cuk Thi Kim. 2017. Reading comprehension and translation performance of English linguistics students of Hung Vuong University: A correlational study. International Journal of English Language \& Translation Studies 5(3): 79-85. https://www.academia.edu/35675528/Reading_Comprehension_and_ Translation_Performance_of_English_Linguistics_Students_of_Hung_Vuong_ University_A_Correlational_Study. (Last accessed: 5 May 2018). 